\title{
World Nomad Games as a Factor Increasing the Kyrgyz Republic Image
}

\author{
Rahkmatullo Anarkulov', Talantbek Anarkulov², Farida Deidieva ${ }^{3}$, Zhypargul Abdullaeva4* (i) \\ ${ }^{1}$ Department of Pedagogics, Psychology and Physical Training, Osh State University, Osh, Kyrgyzstan \\ ${ }^{2}$ Department of General Surgery, Medical Faculty, Osh State University, Osh, Kyrgyzstan \\ ${ }^{3}$ Industrial Pedagogical College, Osh State University, Osh, Kyrgyzstan \\ ${ }^{4}$ Science and Research Department, Osh State University, Osh, Kyrgyzstan \\ Email: ^jypar.science@oshsu.kg
}

How to cite this paper: Anarkulov, R., Anarkulov, T., Deidieva, F., \& Abdullaeva, Z. (2021). World Nomad Games as a Factor Increasing the Kyrgyz Republic Image. $A d$ vances in Physical Education, 11, 387-394. https://doi.org/10.4236/ape.2021.114032

Received: September 10, 2021

Accepted: October 13, 2021

Published: October 18, 2021

Copyright (c) 2021 by author(s) and Scientific Research Publishing Inc. This work is licensed under the Creative Commons Attribution International License (CC BY 4.0) http://creativecommons.org/licenses/by/4.0/

\begin{abstract}
This article discussing the role and significance of the World Nomad Games (WNG) as a factor in enhancing the image of the Kyrgyz Republic, including the revival, popularization, development and internationalization of the primordially national sports, games and physical exercises, and competitions, the identity of ethnic groups. The most important mission of the World Nomad Games aimed at the development of physical culture and ethnocultural movement internationally, as the legacy of human civilization.
\end{abstract}

\section{Keywords}

World Nomad Games, Kyrgyz Republic, Ethnophysical Culture, National Sport, Games, Competitions, International Sport Movements

\section{Introduction}

The development of Kyrgyz national physical culture among the general population is one of the priority directions of the internal policy of the Kyrgyz Republic. In the law of the Kyrgyz Republic "on Kyrgyz national sports and games", special attention is paid to the development of national sports and games in the republic, as a strategically important area.

Physical culture has an appropriate motor activity in the form of physical exercises, who effectively form the necessary skills, physical abilities, optimize health condition and performance (Eremenko et al., 2019).

The relevance of cognition of the backbone factor of the World Nomad Games (WNG) is not only of historical interest, but also of theoretical and practical importance including thousands of folk games, competitions, shows, amuse- 
ments, folk physical exercises, types of ethnosport, as well as historical and modern complex games (Mambetaliev, 2017a).

Scientific classification of Kyrgyz outdoor games proposed by Professor Kh. F. Anarkulov, describing up to 298 games, their content, rules, features of functioning, influence on development of students skills and abilities, gave recommendations on their use in the process of learning at school and during children's leisure activities (Aryk, 2016).

The socio-historical conditions of the initial transition period stage in Kyrgyzstan are naturally determined the relevance of traditional physical culture development in various aspects and were also researched by M. Saralaev (2005).

For the successful solution of the tasks set for physical culture and sports organizations, federations of national sports and all citizens of the Kyrgyz Republic, a combination of three main factors are necessary:

1) Achieve high sports performance at all International competitions;

2) To ensure the mass participation of the Kyrgyz national sports, outdoor games and physical exercises;

3) Strengthen the material and mental base of physical culture and sports industry following the requirements of the international standards (Gosteva, 2018; Martynenko, 2018).

A more effective solution to the above tasks in international practice is to hold large international sports competitions that allow the organizing country to declare itself as a sovereign government that has achieved high performance in politics, economics, ideology, in the development of physical culture and sports in general.

Today the most practical competitions in the world of big sport are the competitions of the Olympic movement (Ivanov, 2019). The World Nomad Games should rightfully be considered as such competition games. The history of the World Nomad Games dates back to the epic Manas. The game and competitions organized at the annual commemoration, the funeral feast of Kokotay, something other than organizing and holding analogs of the largest regional games of all nomadic peoples and not only them, there were also presentations of the peoples of sedentary cultures. This can be judged by the geography, scale, scope and variety of games, where the truest fighters, gifted, skillful and strong, won. Similar competitions of nomadic peoples in the open air and natural sports arenas (conditions) of many-sided sports fans, as well as thousands of audience, spectators. The geography of Kokotay's commemoration covered a vast territory from Beijing, Turpan to Enesay (Yenisei) including Central Asia, Altai, Khangai, Eastern Siberia, Mongolia, covering the border of present-day Eurasia, with the peoples of the nations there. Games organized at Kokotay's funeral included chabysh, zhorgo salish, zhamba atmay, er sayysh, oodarysh, zhoo zharash, kurosh and many other games (Azizbaev, 2020).

Rationale for carrying out this research is explanation of World Nomad 
Games mission as ethnocultural types of physical culture games; World Nomad Games features including uniqueness of World Nomad Games, which is not limited to the national borders and contributing to preservation of ethnocultural heritage; World Nomad Games Contents.

\section{World Nomad Games Mission}

The World Nomad Games is a large-scale international project (Figure 1), modern international sports competitions of nomadic peoples, in the past, in ethnic and ethnocultural types of physical exercises. The competitions of the World Nomad Games are based on folk games and physical exercises of many nomadic peoples from different regions. World Nomad Games the revival of ethno-physical culture, ethnocultural of nomadic peoples in the context of world globalization.

Although Kyrgyzstan already had experience in holding major sporting events, such as the World Sambo Championships among police officers, Asia in weightlifting, freestyle, Greco-Roman and women's wrestling, judo, sambo, etc., only in 2014, the city of Cholpon-Ata (Kyrgyz Republic) received the right to host the first, second and third World Nomad Games, which in itself pleases the initiative of Kyrgyzstan.

The most important mission of the World Nomad Games is aimed at the development of physical culture and ethnocultural movement in the International arena, as the legacy of human civilization. It also includes the revival, popularization, development and internationalization of nominal sports, games and physical exercises, and competitions of nomadic peoples, the development and careful preservation of ethnocultural, the identity of ethnic groups to foster a respectful relationship between ethnic groups.

Thus, the World Nomad Games included ethnocultural, ethnophysical culture, ethno-sport and science. There is no doubt that the geography and the traditionally traditional national sports included in the program of the World Nomad Games will expand from year to year, which may well act as an analog of

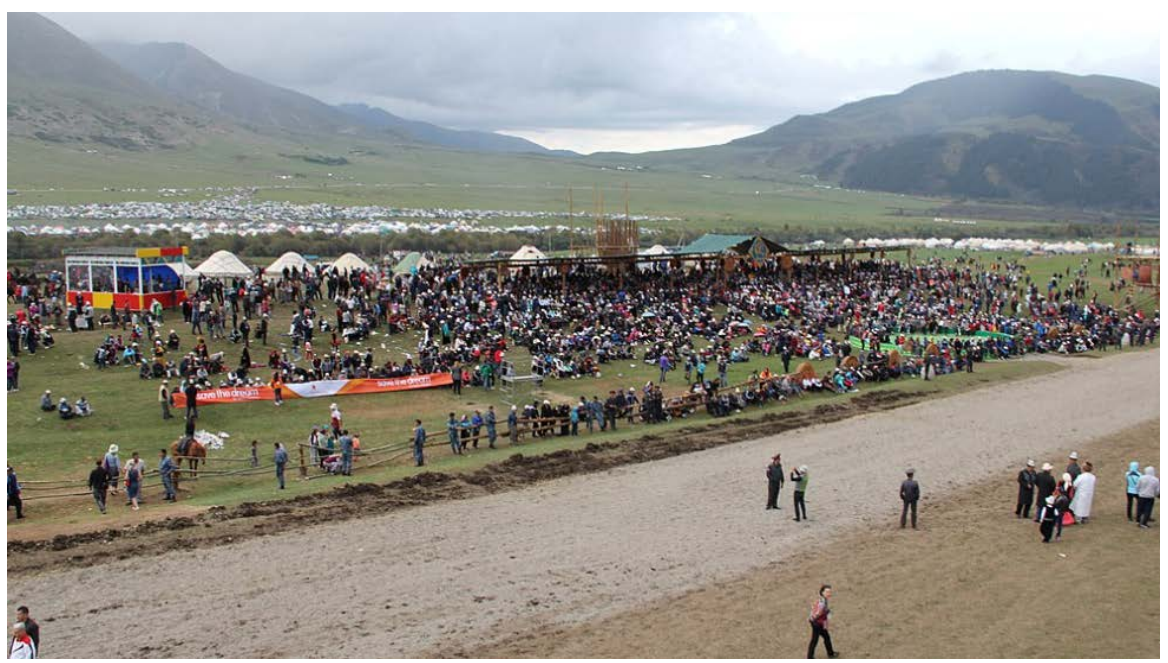

Figure 1. 2016 Nomadic Games Kyrgyzstan (Wikipedia, 2021). 
the Olympic Games, peoples who in the recent past are a nomadic way of life.

The volume echoes the main motto of the World Nomad Games "By one power! With one spirit!", which corresponds to the goals and objectives of the nomad games and most importantly to the meaning and content of the World Nomad Games. Proof of the recognition of the above facts can be the invitation by the King of Saudi Arabia of the full delegation of the republic's athletes to participate in the 2019 ethnofestival (World Nomad Games, 2018).

\section{World Nomad Games Features}

One of the features of the World Nomad Games is, in addition to the main program of the games, a great interest in the scientific side of the games and ethnic cultures of nomadic peoples. The uniqueness of World Nomad Games is the mission, which is not limited to the national borders, contributes to the preservation of the ethnocultural heritage of the peoples of the world through the organization of complex competitions in types of ethnosport (Mambetaliev, 2017b).

In this regard, the Kyrgyz Republic shows a special interest in the Altai civilization, respects scientists and researchers who contribute to the study of the language, history of development, culture of peoples belonging to the Altai linguistic group and Altai civilization. It is no coincidence that in 2017 the republic hosted an international scientific conference Altai civilization and related peoples of the Altai language family. Based on the decision and resolution of the conference on the eve of the $3^{\text {rd }}$ World Nomad Games, the $61^{\text {st }}$ International Conference "Folk Games and Related Customs in the Altai World" PIAC-2018: The above-mentioned Altaiestic conference brought to the judgment of scholars and the public a fairly wide range of scientific problems in history development of nomadic civilizations, archeology, philology, linguistics, ethnology, ethno-physical culture, culture and other areas.

There is no doubt that over time, the World Nomad Games can gain the same popularity and respect as the modern Olympic and regional games. Following the goals and objectives, the efforts being made were directed towards proving and showing the international community that games of nomadic peoples existed in the past.

The dynamic development of the national economy and infrastructure of Kyrgyzstan, the strong political will of the President and the Government of the Republic, internal social stability against the background of an effective interethnic policy of the government has secured the authority of a leader in the Central Asian region for Kyrgyzstan.

Kyrgyzstan is known in the international arena as a Parliamentary, peaceful, open-policy country. This fact is in full accordance with the following types of physical exercises: Tyiyn enmey; Dzhigitovka; Camel and horse racing; Donkey racing and other games of the peoples of the world.

Scientific Forum of the $3^{\text {rd }}$ World Nomad Games "World Nomad Games: Historical Heritage and Future". The objectives of the forum were: to study the 
role and place of the culture of the nomadic peoples of the world in the development of human civilization; research of theories of civilization of mankind and the formation of the theory of civilization of nomads; history and culture of nomadic peoples; a study of motor culture and the relationship of folk games with the customs and traditions of peoples; a study of the phenomenon of world games of nomads, as the historical heritage of the peoples of the world, the current state and the future; scientific and methodological substantiation of various aspects of traditional physical culture and ethnosport. Ethnosport is a new institutional form containing traditional types of physical activity, including national sports, and everywhere revived as historical reenactment traditional games of indigenous peoples; expands ideas about sports as a sociocultural phenomenon in the context of acquiring a new function encouraging and preservation of ethnocultural diversity (Kylasov, 2011).

Formation of a permanent scientific "platform" of the scientific community of researchers, scientists and organizers of science within the framework of the world games of nomads.

\section{World Nomad Games Content}

Traditional intellectual games: tolguz korgool (Kyrgyz Republic); mangala (Ture Republic); competition on arrows from a traditional bow (Kyrgyz, Turks, Koreans); arrow from a traditional bow on horseback (Kyrgyz, Turks, Koreans) and at a distance (Hungary).

Competitions in the national types of hunting "Salburuun" among the Kyrgyz: burkut saluu is hunting with a golden eagle; Dalba is a hunting with a falcon; Taigan zarysh is a greyhound dog racing.

The innovation for the $3^{\text {rd }}$ WNG was the great nomad wrestling was conducted according to the rules of free belt wrestling; the participants were the absolute winners of 13 national types of wrestling: alish, aba guresh, goresh, gushtini milli kamarbandi, gyulesh, kazakh kuresy, kurash, kyrgyz kurosh, pakhlavani, sambo, sumo. The Books of the Great Winners is a chronicle book that stores the achievements of the great winners of the World Nomad Games, artistically designed in a traditional and historical style, reflecting the characteristics of the nomadic peoples of the world.

Each participating country could present its national sports, folk games, traditions and fun in the form of demonstration performances, which are not part of the competitive sports program: Kok bory on horseback (Figure 2); Kok bory on yaks; Kyz kuumay; Horse racing; At chabysh is a long distance racing; Kunan chabysh is races of two-year-olds; Zhorgo salish is pacers' race; Byshty zhorgo is a race of three-year-old pacers; Smooth jumps; Remote equestrian run.

Horse racing named Kok boru is a national horse racing game. Er enish is a national horseback wrestling (Figure 3) (Kyrgyz Republic). Competitions in national sports types of wrestling: Alysh (Kyrgyz Republic); Ashyrtmaly Aba 


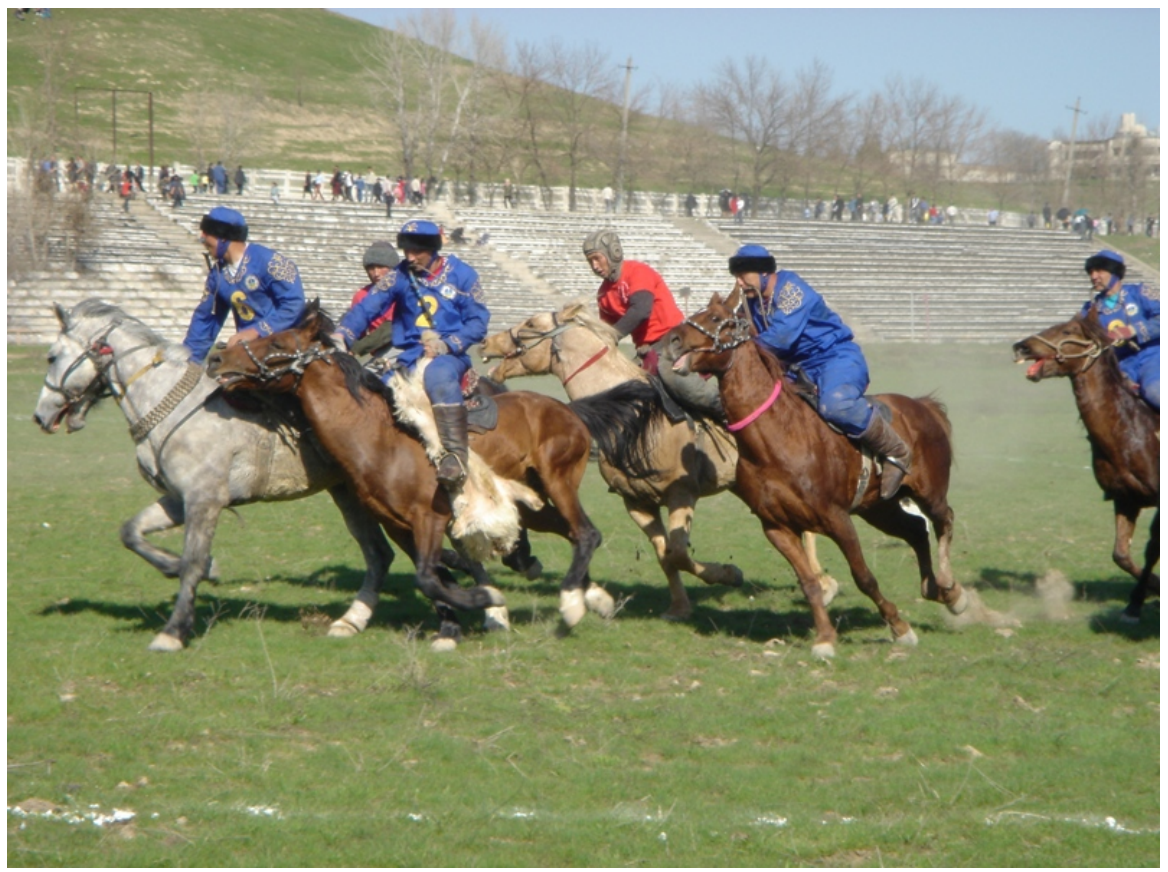

Figure 2. A game of kokpar, Kazakhstan (Wikipedia, 2021).

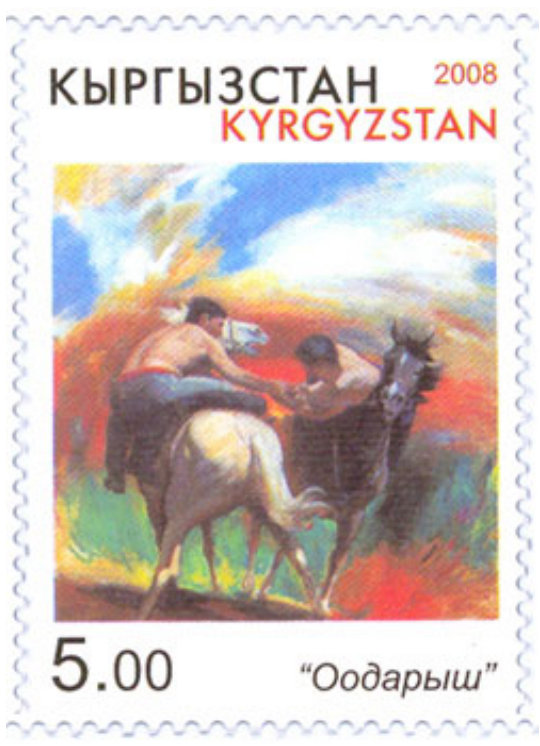

Figure 3. Traditional Kyrgyz horse wrestling known as Oodarysh (Wikipedia, 2021).

Gureshi (Turet Republic); Goresh (Turkmenistan); Gushtin milli kamarbandi (Tajikistan); Gulesh (Republic of Azerbaijan); Kazakh kuresy (Republic of Kazakhstan); Kurash (Republic of Uzbekistan); Kyrgyz kuresh (Kyrgyz Republic); Mongol boh (Mongolian); Phlavani (Islamic Republic of Iran); Sambo (Russian Federation); Ssireum (Republic of Korea); Sumo (Japan); The great nomad wrestling is the united free belt wrestling of the nomads.

Tug of war competition of the peoples of the world; Mass wrestling national competition (Russian Federation); Arm wrestling is a competition of the peoples of the world. 
Strengthening and further development of interreligious and intercultural dialogue, mutual understanding, friendship, harmony and cooperation between ethnic groups and peoples of the world and demonstrating their cultural diversity.

Political dimension of Games is not only related to foreign policy, but also to the government internal political strategy with preparation and organization of similar competitions (Voinov, 2013).

Particular attention paid to environmental issues, especially the leopards snow has been chosen as the official mascot of the $3^{\text {rd }}$ World Nomad Games. Thus, the organizers of the games wanted to draw the attention of the world community to the protection and preservation of the habitat of this unique animal.

The ethno-cultural program included the ethno-festival "Universe of nomads", within which the following was presented: storytelling (epics, legends, fairy tales); ethnobazaar (craft fair and master classes); ethnodom (dwelling of nomads); ethnic fashion (primordially traditional and modern clothes); ethnos (folk dance); ethno hit (pop song, folklore); nomadic theater (drama and puppet performances in open areas); contemporary art (exhibitions).

The ethnosport program included 37 types of competitions: National Games: Kyrgyz National Game "Ordo" 583 athletes from 29 countries took part in them. Competitions were held in 10 types of ethnosport. 1200 people took part in the cultural program. The television broadcast reached an audience of 230 million. The competition was held from September 9 to September 14, 2014 in the city Cholpon-Ata.

The Second World Nomad Games were held from 3 to 8 September 2016 at the same place. They hosted 1200 athletes from 62 countries. Competitions were held in 26 types of ethnosport. The television broadcast reached an audience of 500 million.

The opening ceremony of the third World Nomad Games was held on September 2, 2018. The actions of the games themselves took place in 3 locations: a hippodrome and a fitness center in the city of Cholpon-Ata, the Kyrchyn gorge. About 3000 athletes from 80 countries took part in these competitions. Competitions were held in 37 types of ethnosport.

\section{Conclusions}

The World Nomad Games are aimed at the development of the ethnosport and ethnocultural movement in the world as a heritage of human civilization. The mission of the Games is to revive, develop and preserve ethnoculture, the identity of ethnic groups and peoples of the world to foster a tolerant relationship between ethnic groups and peoples.

The aim and objectives of the games were: preservation of the historical cultural heritage and diversity of the peoples of the world in the era of globalization; development of the world ethnosport movement; popularization of the development and introduction to the international arena of types of ethnosport, pri- 
mordially traditional games and competitions of ethnic groups and peoples of the world; assistance to the scientific, organizational and methodological substantiation of the ethnosport movement of the types of ethnosport, primordial traditional games and competitions of ethnic groups and peoples of the world.

Research results, implications for future research and reflections are expected from World Nomad Games that will be held in foreign countries. Implementation of World Nomad Games elements in the university physical education courses.

\section{Conflicts of Interest}

The authors declare no conflicts of interest regarding the publication of this paper.

\section{References}

Azizbaev, S. S. (2020). Traditional Types of Folk Games and Competitions of Nomadic Peoples (on the Example of the Culture of the Kyrgyz). Omsk University Bulletin. Series "Historical Sciences", 1, 187-192. https://doi.org/10.24147/2312-1300.2020.7(1).187-192

Aryk, D. (2016). The use of Kyrgyz Outdoor Games for the Development of Physical Fitness of Students. Symbol of Science, 3, 19-23.

Eremenko, V. N., Medvedeva, A. S., \& Levchenko, A. A. (2019). The Role of Physical Culture in Human Life. Azimuth of Scientific Research: Pedagogy and Psychology, 8, 353-355. https://doi.org/10.26140/anip-2019-0803-0091

Gosteva, S. R. (2018). The Legal Field for the Development of Physical Culture and Sports in the Russian Federation. Eurasian Forum, 1, 241-257.

Ivanov, V. D. (2019). Olympic Games: A Historical Excursion. Physical Education. Sport. Tourism. Motor Recreation, 4, 39-45.

Kylasov, A. V. (2011). Ethnosport Methodology and Terminology. Sports Science Bulletin, 5, 41-43.

Mambetaliev, K. U. (2017a). Demonstration Essence of Sport as a System-Forming Factor of the World Nomad Games. MS, 12, 122-125.

Mambetaliev, K. U. (2017b). The Uniqueness of the World Nomad Games. Manuscript, 12, 127-129.

Martynenko, S. E. (2018). International Legal Foundations of Sports Diplomacy. Legal Science, 25-29.

Saralaev, M. K. (2005). The Problems of Kyrgyz National Kinds of Sports. Materials of the Conference "The Current Government and Perspectives of the National Physical Culture Development”, Bishkek, 129-134.

Voinov, D. E. (2013). Typologization of the Influence of Politics on the Modern Olympic Games. Journal of Sociology and Social Anthropology, 16, 21-38.

Wikipedia (2021). 2016 Nomadic Games. https://en.wikipedia.org/wiki/World_Nomad_Games\#/media/File:Save_the_Dream_in _Nomadic_village_(30000675335).jpg

World Nomad Games (2018). Sport Types. http://www.worldnomadgames.com/ru/ 